\title{
Ixora coccinea Enhances Cutaneous Wound Healing by Upregulating the Expression of Collagen and Basic Fibroblast Growth Factor
}

\author{
Aadesh Upadhyay, ${ }^{1,2}$ Pronobesh Chattopadhyay, ${ }^{1}$ Danswrang Goyary, ${ }^{1}$ \\ Papiya Mitra Mazumder, ${ }^{2}$ and Vijay Veer ${ }^{1}$ \\ ${ }^{1}$ Division of Pharmaceutical Technology, Defence Research Laboratory, DRDO, Tezpur, Assam 784001, India \\ ${ }^{2}$ Department of Pharmaceutical Sciences, Birla Institute of Technology, Mesra, Ranchi, Jharkhand 835215, India
}

Correspondence should be addressed to Pronobesh Chattopadhyay; chattopadhyay.drl@gmail.com

Received 4 September 2013; Accepted 5 December 2013; Published 29 January 2014

Academic Editors: R. Couture, S. Cuzzocrea, A. Fernandez-Guasti, and B.-N. Wu

Copyright @ 2014 Aadesh Upadhyay et al. This is an open access article distributed under the Creative Commons Attribution License, which permits unrestricted use, distribution, and reproduction in any medium, provided the original work is properly cited.

\begin{abstract}
Background. Ixora coccinea L. (Rubiaceae) has been documented for traditional use in hypertension, menstrual irregularities, sprain, chronic ulcer, and skin diseases. In the present study, I. coccinea was subjected to in vitro and in vivo wound healing investigation. Methods. Petroleum ether, chloroform, methanol, and water sequential I. coccinea leaves extracts were evaluated for in vitro antioxidant, antimicrobial, and fibroblast proliferation activities. The promising I. coccinea methanol extract (IxME) was screened for in vivo wound healing activity in Wistar rat using circular excision model. Wound contraction measurement, hydroxyproline quantification, and western blot for collagen type III (COL3A1), basic fibroblast growth factor (bFGF), and Smad-2, $-3,-4$, and -7 was performed with 7 -day postoperative wound granulation tissue. Gentamicin sulfate ( $0.01 \%$ w/w) hydrogel was used as reference standard. Results. IxME showed the potent antimicrobial, antioxidant activities, with significant fibroblast proliferation inducing activity, as compared to all other extracts. In vivo study confirmed the wound healing accelerating potential of IxME, as evidenced by faster wound contraction, higher hydroxyproline content, and improved histopathology of granulation tissue. Western blot analysis revealed that the topical application of I. coccinea methanol extract stimulates the fibroblast growth factor and Smad mediated collagen production in wound tissue.
\end{abstract}

\section{Background}

The World Health Organization estimated that $80 \%$ of the world's population still relies on plant-based medicines for their primary health care, and skin related disorders specially wounds, which is the most common reason for medical visits in the developing countries. Wounds and wound management therapy have a long history and in the different Ayurvedic classics of India like Charaka Samhita, Sushruta Samhita, and Ayurveda Siksha approximately $70 \%$ of the wound healing medicines are of plant origin. In the last few decades, traditional wound healing plants have received enough attention for scientific investigations [1-3], where pathophysiological process of wound healing and various related activities such as fibroblast growth stimulation and antioxidant and antimicrobial activities has been extensively studied and correlated to the rationale of the traditional plant medicines $[1,4,5]$. In thrust of finding for an effective wound healing herb, Ixora coccinea L. (Rubiaceae) was selected for the in vitro and in vivo wound healing investigations. I. coccinea is a small-medium evergreen shrub, widely cultivated ornamental plant throughout South Asian regions, and, used in the treatment of various ailments like infection, hypertension, menstrual irregularities, sprain, chronic ulcer, and skin diseases including cutaneous wounds [6-8]. The plants have been reported for cytotoxic, antitumor, antimicrobial, and anti-inflammatory activity [7, 9-13]. The earlier reports of $I$. coccinea indicated the preliminary wound healing and antimicrobial properties of flower and root extracts $[6,8]$, but the effect of $I$. coccinea leaf was not properly investigated on various aspects of wound healing. Therefore, the present study was aimed to investigate the effect of $I$. coccinea leaves 
extract on fibroblast proliferation and related growth factors involved in collagen production pathway in wound granulation tissue.

\section{Materials and Methods}

2.1. Cell Line, Bacterial Culture, and Chemicals. Human dermal fibroblast (HDF10605) cell line was procured from Sigma Aldrich. The bacterial strains Bacillus subtilis (MTCC 441), Staphylococcus aureus (MTCC 3160), Streptococcus mutans (MTCC 890), Escherichia coli (MTCC 443), Klebsiella pneumoniae (MTCC 109), and Pseudomonas aeruginosa (MTCC 741) were obtained from Institute of Microbial Technology (IMTECH), Chandigarh. Mueller-Hinton broth, butylated hydroxytoluene (BHT), gallic acid, 2,2diphenyl-1-picrylhydrazyl scavenging (DPPH), and nitroblue tetrazolium (NBT) were purchased from Sigma. The Folin-Ciocalteu reagent, phenazine methosulfate (PMS), $\beta$-nicotinamide adenine dinucleotide $(\mathrm{NADH})$, potassium ferrocyanide, trichloroacetic acid (TCA), ferric chloride, hydrogen peroxide $\left(\mathrm{H}_{2} \mathrm{O}_{2}\right)$, phenazine methosulfate fluoride (PMSF), dimethyl sulphoxide (DMSO), and 3-(4,5-dimethylthiazol-2-yl)-2,5-diphenyltetrazolium bromide salt (MTT) purchased were from Himedia (Mumbai, India). All primary and secondary antibodies and BCIP (5-bromo-4-chloro- $3^{\prime}$ indolyphosphate $\mathrm{p}$-toluidine salt)-NBT reagent were purchased from Santa Cruz Biotech, Inc. (Texas, USA). The solvents and chemicals which are not mentioned in the text were of analytical grade.

2.2. Preparation of Extracts. I. coccinea leaves were collected during September-October (2011) from campus garden of Defence Research Laboratory, Tezpur, Assam, (India), and authenticated at Botanical Survey of India, Shillong (India), and the specimen sample deposited (Acc. no. 081168). About $100 \mathrm{~g}$ of shade dried leaves powder was successively extracted with petroleum ether, chloroform, methanol, and water at $1500 \mathrm{lb}$ at room temperature in Accelerated Solvent Extractor (ASE 1.5, Dionex, USA). The extraction was considered complete when the initial color of the percolate gradually changed to colorless. Each solvent extract was concentrated in rotary evaporator (Rotavac, Heidolph2, Germany) under reduced pressure and the water extract was freeze-dried. Preliminary phytochemical screening was performed as described earlier [14].

2.3. Antimicrobial and Antioxidant Wound Healing Relevant Assays. Agar broth dilution technique was used in the determination of minimum inhibitory concentration (MIC) in antimicrobial screening according to Hayouni et al. [15].

Antioxidant evaluations including DPPH free radical and superoxide anion radical scavenging activity (SRSA), ferric ion reducing antioxidant power (FRAP), and total phenolic content were performed as described earlier [16-19].

2.4. Fibroblast Proliferation Assay. Human dermal fibroblast cells were cultured in DMEM containing 10\% Fetal Bovine Serum (FBS) and antibiotics $(100 \mathrm{U} / \mathrm{mL}$ penicillin and
$100 \mathrm{U} / \mathrm{mL}$ streptomycin) in a humidified $\mathrm{CO}_{2}$ incubator with $5 \% \mathrm{CO}_{2}$ at $37^{\circ} \mathrm{C}$. Media were replaced every alternate day. Cells were harvested on confluency, using 0.05\% TrypsinEDTA and subcultured in fresh media for producing single cell suspension.

The fibroblast proliferation assay was performed as described by Adetutu et al. [4]. The cells were counted using a Scepter 2.0 Automated Cell counter (Millipore, USA) and seeded at a density of $1 \times 10^{3}$ cells per well in 96-well plate excluding the first row and maintained at $37^{\circ} \mathrm{C}$ in humidified $5 \% \mathrm{CO}_{2}$ atmosphere with $10 \%$ FBS. The medium was replaced after $24 \mathrm{~h}$ incubation with DMEM containing 0.5\% FBS and extract samples. All samples were dissolved in DMSO. The final concentrations of extracts ranged from 1.56 to $100 \mu \mathrm{g} / \mathrm{mL}$ and for DMSO 0.4\% v/v. DMEM/0.5\% FBS (with DMSO) and DMEM/10\% FBS serve as normal control and growth stimulation controls. After $48 \mathrm{~h}$ of incubation cell viability was assayed by MTT assay method. The MTT solution $(5 \mathrm{mg} / \mathrm{mL})$ was added to each well before $4 \mathrm{~h}$ of culture termination. DMSO was added to each well and optical density was measured at $570 \mathrm{~nm}$, using a microplate reader (SpectraMax Plus 384, Molecular Devices, USA). Each sample was assayed in triplicate and three independent tests were performed.

2.5. Hydrogen Peroxide Induced Oxidative Stress. Hydrogen peroxide $\left(1.0 \times 10^{-4} \mathrm{M}\right)$ was used to induce oxidative stress as described by Annan and Houghton [5]. Dermal fibroblast cells were seeded in 96 -well plates $\left(5 \times 10^{3}\right.$ cells/well) containing DMEM/10\% FBS, incubated at $37^{\circ} \mathrm{C}$ in humidified $5 \%$ $\mathrm{CO}_{2}$ atmosphere. After $24 \mathrm{~h}$ the growth medium was replaced with fresh DMEM containing different concentrations of extracts $(1.56-100 \mu \mathrm{g} / \mathrm{mL})$ and simultaneously exposed to $1.0 \times 10^{-4} \mathrm{M}$ hydrogen peroxide and incubated for $3 \mathrm{~h}$ at $37^{\circ} \mathrm{C}$. Catalase $(250 \mathrm{U} / \mathrm{mL})$ was used as positive control. After the incubation, cell viability was assessed by MTT assay method. Each sample was assayed in triplicate and three independent tests were performed.

\subsection{Wound Healing Activity}

2.6.1. Animals. Healthy adult Swiss albino male mice (20$25 \mathrm{~g}$ ) and male Wistar rats (250-300 g) housed in Defence Research Laboratory (DRL), Tezpur, Assam (India), were acclimatized for 3 days. They were given free access to food and water ad libitum. The experiments were performed according to the Institutional Animal Ethical Committee guidelines (IAEC/DRL/05/July/2011) of DRL, Tezpur.

2.6.2. Acute Skin Irritation and Toxicity Study. The acute skin irritation and toxicity study was performed for $1 \%$ and $2.5 \%$ (w/w) IxME hydrogel according to the OECD guidelines 402 (OECD guidelines, 1987) [20]. Hydrogel was applied on the shaved back of the mice and monitored for 14 days for abnormal skin response including irritation, redness itching, inflammation, and other related symptoms.

2.6.3. Animal Grouping and Excision Wound Creation. All Wistar rats were anesthetized with sodium phenobarbitone 
(40 mg/kg) intraperitoneally (i.p.). Circular $20 \mathrm{~mm}$ diameter wounds were caused on dorsal skin of each animal up to the depth of loose subcutaneous tissue using surgical scissor and forceps. Animals were randomly divided into four groups: nontreated (group I), vehicle control (Carbopol 934 containing 5\% propylene glycol, group II), I. coccinea methanol extract (IxME, 2.5\% w/w, group III), and gentamicin sulfate $(0.01 \% \mathrm{w} / \mathrm{w}$, group IV). Each group contains 20 animals and hydrogel formulations were applied topically once daily until complete epithelialization. On the 7th postoperative day, onethird of animals were euthanized and wound granulation tissues (excluding any underlying muscle and extraneous tissue) were harvested. A portion of harvested tissue was immediately stored in liquid nitrogen for further analysis and another portion was fixed in $4 \%$ formaldehyde for histopathological evaluations. Half of the remaining animals were euthanized on day 15 after injury; the entire granulation tissue was used for histopathological assessment and remaining animals were observed until complete epithelialization [21].

2.6.4. Wound Contraction Rate and Hydroxyproline Content Estimation. The progressive changes of wounded area were photographed (Nikon Coolpix-S3000 camera) and evaluated by using special size analysis software-ImageJ (National Institutes of Health, Maryland, USA) - as described earlier [21].

Hydroxyproline content was analyzed on day 7 after injury granulation tissue as described by Upadhyay et al. [21]. Tissue hydrolysate samples were mixed with $1 \mathrm{~mL}$ of $10 \mathrm{mM}$ $\mathrm{CuSO}_{4}$ followed by the addition of $1 \mathrm{~mL}$ of $2.5 \mathrm{~N} \mathrm{NaOH}$ and then $1 \mathrm{~mL}$ of $6 \% \mathrm{H}_{2} \mathrm{O}_{2}$. The solution was mixed and incubated at $80^{\circ} \mathrm{C}$ for $5 \mathrm{~min}$ with frequent vigorous shaking. Upon cooling, $4 \mathrm{~mL}$ of $3 \mathrm{~N} \mathrm{H}_{2} \mathrm{SO}_{4}$ was added with agitation. Finally, $2 \mathrm{~mL}$ of $5 \%$-dimethyl amino benzaldehyde was added and incubated at $70^{\circ} \mathrm{C}$ for $15 \mathrm{~min}$. Absorbance was measured at $500 \mathrm{~nm}$ using a UV-VIS spectrophotometer (CE7200, CECIL, USA).

2.6.5. Histopathological Evaluation. Granulation tissues were sectioned ( $6 \mu \mathrm{m}$ thick) and stained with hematoxylin-eosin (HE) and Masson's trichrome (MT) stains. Tissues sections were examined for epithelialization, inflammatory cell infiltration, fibroblast proliferation, neovascularization, and collagen deposition.

2.6.6. Western Blot Analysis. Western blot analysis was performed as described by Upadhyay et al. [21]. Protein concentration was estimated in tissue homogenate using Bradford reagent (Sigma, Germany). Primary antibody COL3A1mouse monoclonal IgG $_{1}$ (sc-271249), bFGF-mouse monoclonal $\operatorname{IgG}_{2 \mathrm{a}}$ (sc-74413), Smad 2-goat polyclonal IgG (sc6200), Smad 4-rabbit polyclonal IgG (sc-7154), Smad 7mouse monoclonal IgG $_{1}$ (sc-365846), $\beta$-Actin-mouse monoclonal $\operatorname{IgG}_{1}$ (sc-47778), and respective secondary antibody goat anti-mouse IgG-AP (sc-2008), rabbit anti-goat IgGHRP (sc-2768), and goat anti-rabbit IgG-AP (sc-2007) were purchased from Santa Cruz Biotech. (USA). Smad 3-rabbit polyclonal IgG (Cat-10832) was purchased from Cayman
TABLE 1: Antibacterial activity of different $I$. coccinea leaves extracts expressed as minimal inhibitory concentration (MIC) in $\mathrm{mg} / \mathrm{mL}$.

\begin{tabular}{lcccc}
\hline \multirow{2}{*}{ Bacteria } & \multicolumn{5}{c}{ MIC (mg/mL) } \\
& IxPE & IxCE & IxME & IxWE \\
\hline Bacillus subtilis (MTCC111) & 2 & $>2$ & 0.125 & 1 \\
Staphylococcus aureus (MTCC3160) & $>2$ & $>2$ & 1 & $>2$ \\
Streptococcus mutant (MTCC890) & $>2$ & 1 & 2 & 2 \\
Escherichia coli (MTCC443) & 2 & 1 & 2 & $>2$ \\
Klebsiella pneumoniae (MTCC109) & $>2$ & $>2$ & 0.25 & $>2$ \\
Pseudomonas aeruginosa (MTCC741) & 2 & 2 & 0.5 & 2 \\
\hline
\end{tabular}

IxPE: I. coccinea petroleum ether extract; IxCE: I. coccinea chloroform extract; IxME: I. coccinea methanol extract; IxWE: I. coccinea water extract. Chloramphenicol was used as positive control (MICs $<90 \mu \mathrm{g} / \mathrm{mL}$ ).

Chemicals (USA). Equal amount of protein was electrophoresed on $12 \%$ SDS-PAGE with $4 \%$ stacking gel (Mini TransBlot, BioRad Laboratories Inc., USA) at $80 \mathrm{~V}$ for $45 \mathrm{~min}$. Proteins were transblotted onto the PVDF membrane (Millipore Corp., USA), and processed with COL3A1, bFGF, Smad$2,-3,-4,-7$ and $\beta$-Actin primary antibodies $(1: 1000)$ and corresponding secondary antibodies $(1: 2000)$. The desired proteins were detected by BCIP-NBT solution and western Max-HRP-Chromogenic detection kit (Amresco, USA). $\beta$ actin was estimated as internal control.

2.7. Statistical Analysis. The results are expressed as means \pm standard deviation (S.D.). Data were statistically analyzed using Dunnett test. A $P$ value $<0.05$ was considered statistically significant as compared to nontreated and vehicle treated group.

\section{Results}

3.1. Extract and Phytochemicals. The yield of the I. coccinea petroleum ether (IxPE), chloroform (IxCE), methanol (IxME), and water (IxWE) was found 3.31, 2.22, 16.33 and $10.92 \%(w / w)$, respectively. The preliminary phytochemical screening of $I$. coccinea extracts showed the presence of alkaloid, flavanoids, terpenes, phenolic, carbohydrate, and saponins in different extracts.

3.2. Antimicrobial and Antioxidant Properties. In the antimicrobial assay, methanol extract was found very active (MIC $0.125-2 \mathrm{mg} / \mathrm{mL}$ ) as compared to other solvent extracts, where the gram positive $B$. subtilis and gram negative $K$. pneumoniae were found the most sensitive (MIC 0.125 and $0.25 \mathrm{mg} / \mathrm{mL}$, resp.). For chloroform extract MIC values were ranging between 1 and $2 \mathrm{mg} / \mathrm{mL}$. Petroleum ether and water extracts showed poor antimicrobial activity against selected pathogens (Table 1).

On the other hand, in DPPH, superoxide radical scavenging activity (SRSA), IxPE, and IxCE were found inactive and showing 0.5 and 6.83 gallic acid equivalents, respectively, in FCR assay (Table 2). IxME and IxWE were potent antioxidant extracts, in which IxME showed higher DPPH scavenging property in comparison to IxWE with $\mathrm{IC}_{50}(\mu \mathrm{g} / \mathrm{mL})$ values 
TABLE 2: Scavenging activity of different $I$. coccinea extracts against DPPH and superoxide anion free radicals and their Folin-Ciocalteu reagent (FCR) reducing capacity.

\begin{tabular}{|c|c|c|c|}
\hline Ixora coccinea & $\begin{array}{l}\text { Scavenging activity against } \\
\left.\text { DPPH radical ( } \mathrm{IC}_{50} \pm \text { S.D. }\right)\end{array}$ & $\begin{array}{c}\text { Scavenging activity against } \\
\text { superoxide radical }\left(\mathrm{IC}_{50} \pm \text { S.D. }\right)\end{array}$ & $\begin{array}{l}\text { FCR reducing capacity } \\
\left(\mathrm{mg}_{\mathrm{GAc}} / \mathrm{g}_{\text {extract }}\right)\end{array}$ \\
\hline IxPE & NA & NA & $0.5 \pm 0.04$ \\
\hline IxCE & NA & NA & $6.83 \pm 0.5$ \\
\hline IxME & $9.63 \pm 1.22$ & $838.03 \pm 21.04$ & $27.75 \pm 0.55$ \\
\hline IxWE & $26.01 \pm 2.66$ & $655.06 \pm 17.83$ & $12.32 \pm 0.43$ \\
\hline Gallic acid & $1.10 \pm 0.39$ & $156.86 \pm 36.39$ & - \\
\hline
\end{tabular}

$\mathrm{IC}_{50}$ values are expressed in $\mu \mathrm{g} / \mathrm{mL}$; NA: not active; S.D.: standard deviation; $\mathrm{IC}_{50}$ : amount of antioxidant necessary to scavenge the initial DPPH/superoxide radical by $50 \% ; \mathrm{mg}_{\mathrm{GAc}} / \mathrm{g}_{\text {extract }}$ : $\mathrm{mg}$ of gallic acid equivalent/gram of extract; GAc: gallic acid; IxPE: I. coccinea petroleum ether extract; IxCE: $I$. coccinea chloroform extract; IxME: I. coccinea methanol extract; IxWE: I. coccinea water extract.

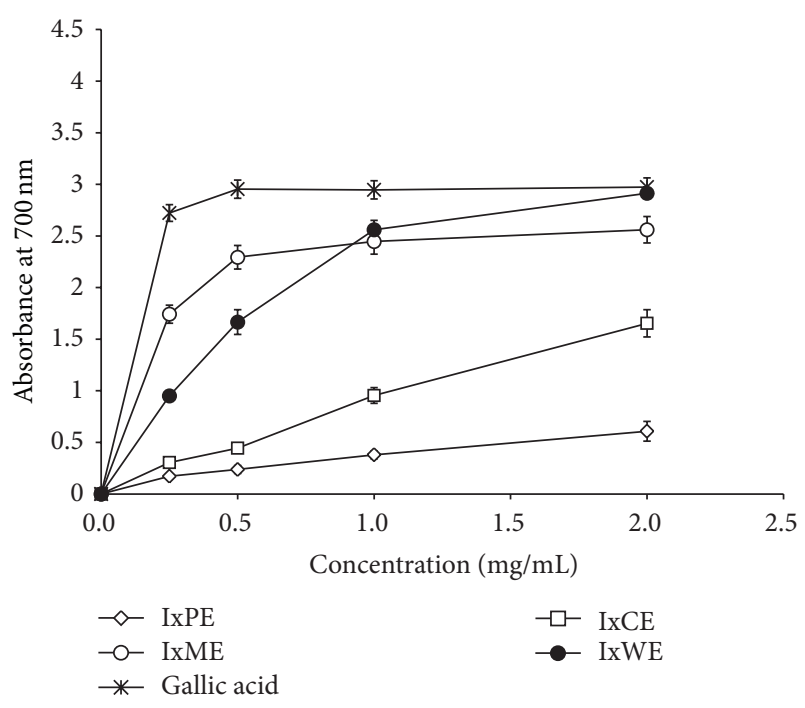

FIGURE 1: Ferric ion reducing antioxidant power (FRAP) of different I. coccinea extracts.

9.63 and 26.01, respectively. On the other hand, $\mathrm{IxWE}\left(\mathrm{IC}_{50}=\right.$ $655.06 \mu \mathrm{g} / \mathrm{mL})$ possess the higher superoxide radical scavenging strength than IxME $\left(\mathrm{IC}_{50}=838.03 \mu \mathrm{g} / \mathrm{mL}\right)$. FRAP and FCR assay data further revealed the antioxidant potency of the IxME and IxWE (Figure 1 and Table 2).

3.3. Fibroblast Proliferation and Viability. Among all the extracts, IxPE decreased the cell viability from 84.02 to $44.99 \%$ in a concentration dependant manner (1.56$100 \mu \mathrm{g} / \mathrm{mL}$ ) (Figure 2(a)). The IxCE, IxME, and IxWE extracts showed the biphasic proliferation response, where the cell viability increased at low concentrations and decreased at higher concentrations. The IxCE exposure for $48 \mathrm{~h}$ increased the cell viability from 89.95 to $98.55 \%$ (1.56 to $6.25 \mu \mathrm{g} / \mathrm{mL})$, however decreased at higher concentrations (Figure 2(a)). The IxME showed the significant fibroblast proliferation activity, which was almost close to the level of positive control $(113.16 \%$ at $12.5 \mu \mathrm{g} / \mathrm{mL})$. On the other hand, IxWE decreased the cell viability from 101.52 to $84.33 \%$ (3.12 to $100 \mu \mathrm{g} / \mathrm{mL}$ ).

The exposure of $\mathrm{H}_{2} \mathrm{O}_{2}\left(1.0 \times 10^{-4} \mathrm{M}\right)$ for $3 \mathrm{~h}$ decreased the cell viability (48.12\%). IxPE synergies the effect of $\mathrm{H}_{2} \mathrm{O}_{2}$ and decreased the cell viability from 47.03 to $35.32 \%$, with increasing concentration (Figure 2(b)). Potent antioxidant IxME and IxWE showed dose dependent protection $(47.33-74.71 \%$ and 47.85-69.47\%, resp.). However, IxCE showed 48.36-60.09\% cell viability at $1.56-100 \mu \mathrm{g} / \mathrm{mL}$.

\subsection{Wound Healing}

3.4.1. Acute Skin Irritation and Toxicity. In skin irritation and toxicity assay, any sign of inflammation and irritation were not observed in both 1 and 2.5\% (w/w) IxME hydrogel. Therefore, high concentration $2.5 \%$ (w/w) IxME hydrogel was selected for in vivo wound healing study.

3.4.2. Wound Contraction. The whole wound area was reduced in parallel to postwound days (Figure 3(a)). Nontreated and vehicle treated animal groups showed $51.3 \%$ and $54.25 \%$ wound contraction on 21 st postoperative days, respectively. On the other hand, IxME treated animal group showed $96.78 \%$ and gentamicin sulfate treated group $89.59 \%$ wound contraction. The contraction rate was significantly higher in IxME treated group as compared to nontreated and vehicle treated control group.

3.4.3. Hydroxyproline Content. IxME and gentamicin sulfate treated group showed significantly increased level of hydroxyproline as compared to nontreated and vehicle treated groups (Figure 3(b)). Although the hydroxyproline content of IxME treatment group was higher as compared to gentamicin sulfate treated group but the data were statistically not significant.

3.4.4. Histopathological Observations. IxME and gentamicin sulfate treated animal groups showed well organized wound healing processes (inflammation, proliferation, and remodeling) in postoperative days. On the other hand, vehicle and nontreated animal groups depict slow rate of epithelialization and dermal layer with lesser collagen bundles (Table 3). Histopathological section of day 7 showed mild to moderate edema and ulcer in nontreated and vehicle treated groups, with abundant polymorphonuclear cell (PMC). The infiltration rate of mononuclear and fibroblast cells were observed low (Figure 4). However, 7-day IxME treated wound tissue 


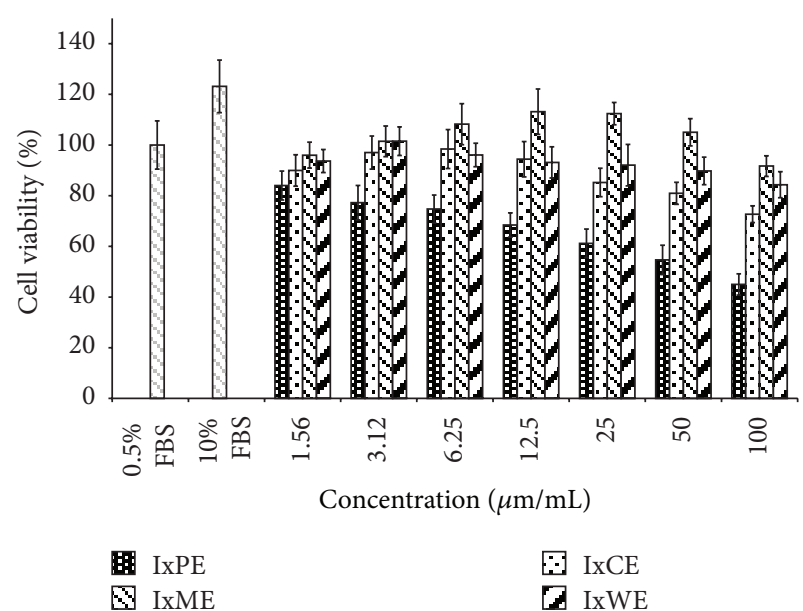

(a)

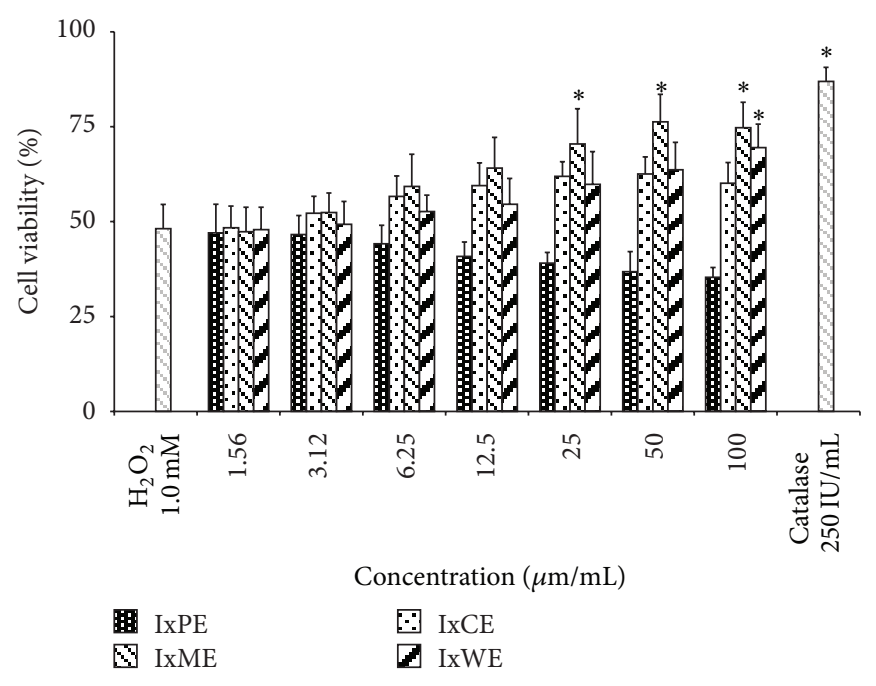

(b)

FIGURE 2: (a) Effect of I. coccinea extracts on human dermal fibroblast proliferation. (b) Protection of human dermal fibroblast cells against $\mathrm{H}_{2} \mathrm{O}_{2}$-induced damage with simultaneous application of different I. coccinea extracts. FBS: Fetal Bovine Serum; Cat-Catalase. Values are expressed as mean \pm SD. Asterisk $(*)$ indicates significantly different $(P<0.05)$ as compared to $\mathrm{H}_{2} \mathrm{O}_{2}$ treated negative treated groups.

TABLE 3: Histopathological evaluation of wound healing process in different treatment groups.

\begin{tabular}{|c|c|c|c|c|c|c|c|c|}
\hline \multirow{2}{*}{ Groups } & \multicolumn{8}{|c|}{ Wound healing process } \\
\hline & S & $\mathrm{U}$ & Ed & PMC & $\mathrm{MNC}$ & FP & $\mathrm{RE}$ & $\mathrm{CD}$ \\
\hline \multicolumn{9}{|l|}{ Day 7} \\
\hline Nontreated & ++ & ++ & ++ & +++ & + & + & - & - \\
\hline Vehicle control & ++ & ++ & ++ & +++ & + & + & $+/-$ & $-1+$ \\
\hline $\operatorname{IxME}(2.5 \%)$ & + & - & - & ++ & ++ & +++ & ++ & ++ \\
\hline Gentamicin sulfate $(0.01 \%)$ & + & - & - & ++ & ++ & ++ & + & + \\
\hline \multicolumn{9}{|l|}{ Day 15} \\
\hline Nontreated & ++ & + & $-/+$ & ++ & +++ & ++ & + & ++ \\
\hline Vehicle control & + & + & - & ++ & +++ & ++ & ++ & ++ \\
\hline $\operatorname{IxME}(2.5 \%)$ & - & - & - & - & + & +++ & +++ & +++ \\
\hline Gentamicin sulfate $(0.01 \%)$ & - & - & - & $-/+$ & + & ++ & ++ & ++ \\
\hline
\end{tabular}

HE and MT staining were scored as mild (+), moderate (++), and severe (+++) for epidermal and/or dermal re-modeling. S: scab; U: ulcer; Ed: edema; PMC: polymorphonuclear cells; MNC: mononuclear cells; FP: fibroblast proliferation; CD: collagen deposition; RE: reepithelialization; IxME: I. coccinea methanol extract.

showed increased density of mononuclear cells with distinct onset of reepithelialization. Edema and ulcerous area were absent in both IxME and gentamicin sulfate treatments. 15day IxME treatment significantly accelerated the cutaneous wound healing as depicted by thick well organized reepithelialized layer, dermis with compact collagen layering, and faster keratinization with intraepithelial cornification, whereas slow reepithelialization with minor ulcer area was noticed in nontreated animal group. Masson's trichrome $(400 \times)$ staining of 7 - and 15 -day postoperative wound granulation tissue depicted the clearer picture of wound healing, where IxME treatment showed increased macrophage and fibroblast density with higher collagen deposition. On the other hand, gentamicin treatment although showed complete reepithelialization with irregular packing of collagen fibers and minor to moderate macrophages infiltration (Figure 4).
In vehicle and nontreated animal groups, collagen bundles were loosely packed and granulation tissues were moderately cellular with mononuclear and fibroblast cells.

3.4.5. Effect of IxME on Granulation Tissue Protein. Western blotting showed significantly increased expression of COL3A1 and bFGF protein in IxME and gentamicin sulfate treated wound granulation tissue (Figure 5). The expression levels of signal transducer protein Smad-2, -3 , and -4 were also significantly increased, whereas the inhibitory protein Smad-7 was found unaltered. Moreover, the expression levels of the COL3A1, bFGF, and Smad proteins $(2,3$, and 4$)$ were significantly higher in IxME treated animals groups in comparison of gentamicin sulphate treated group. The $\beta$-actin was used as an internal control. 


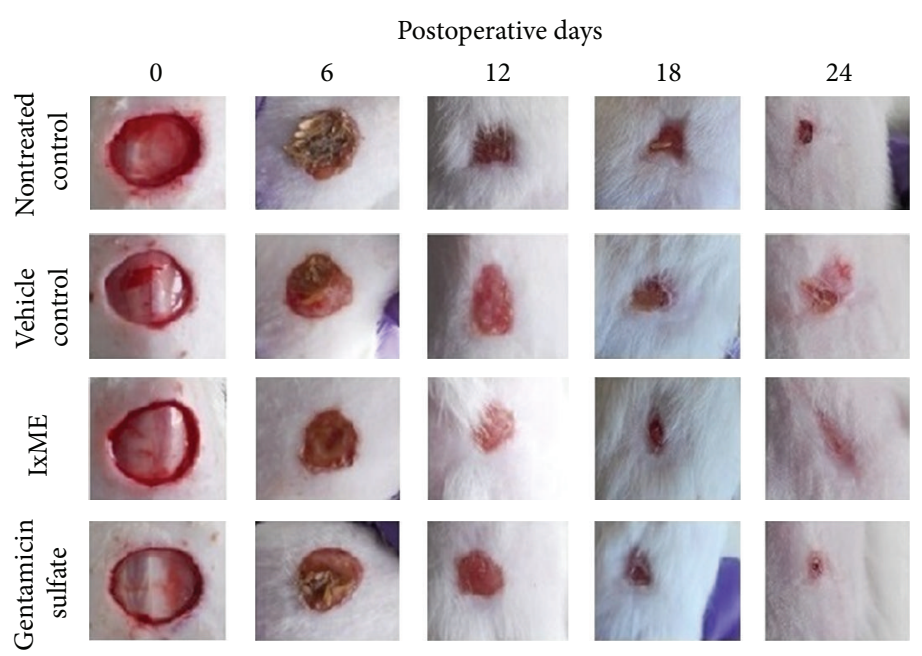

(a)

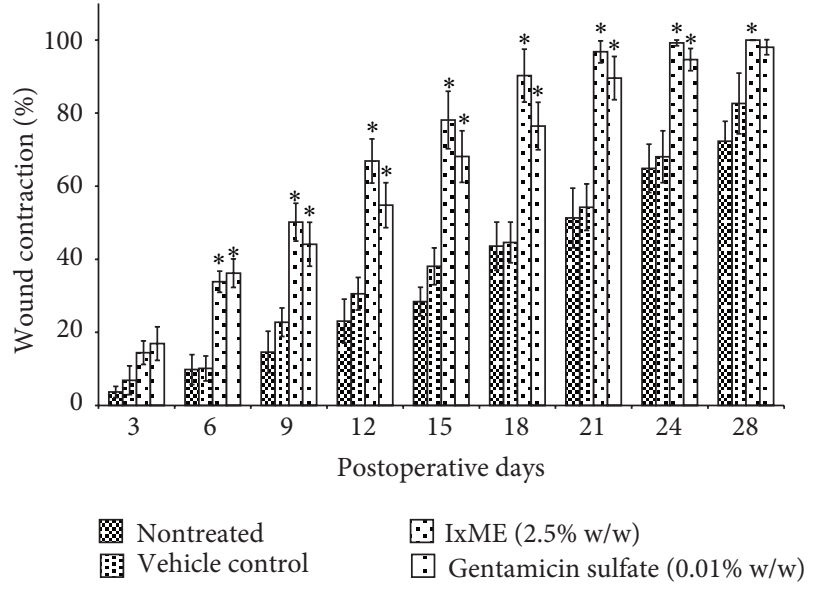

(b)

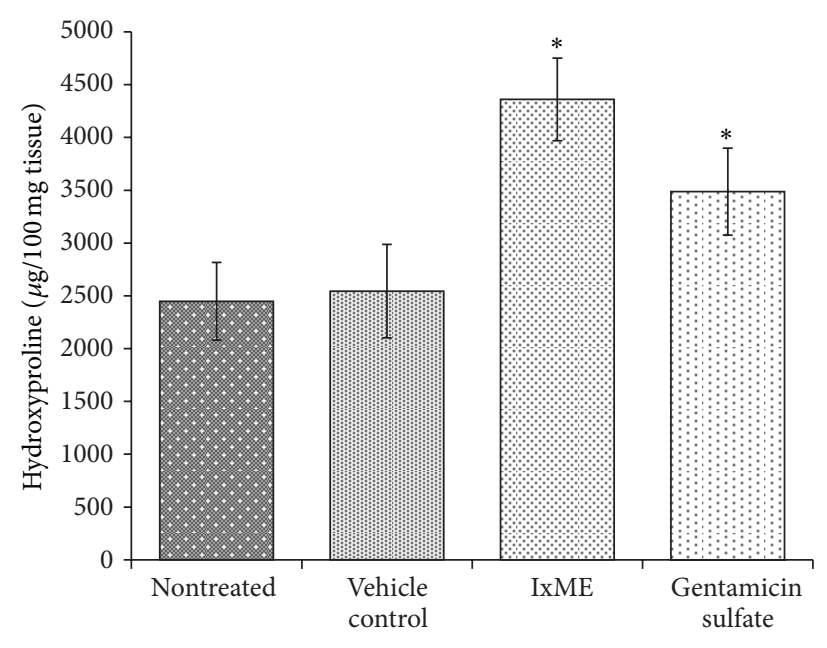

(c)

FIGURE 3: Effect of I. coccinea methanol extract (IxME) on wound healing. (a) Pictorial representation of wound closure in wistar rat. (b) Wound contraction rate. (c) Hydroxyproline content. Values are expressed as mean \pm SD. Asterisk $(*)$ indicates significantly different $(P<0.05)$ as compared to the nontreated and vehicle treated groups.

\section{Discussion}

Cutaneous wound healing is a complex cascade of tissue regenerative and restorative events including chemotaxis, cell division, neovascularization, synthesis, and maturation of new extracellular matrix and remodelling of scar. These events can be broadly categorized into inflammation, proliferation, and remodeling phases of wound healing, which are regulated by several mediators including cytokines and various secreted growth factors.

Although, the wound healing cascade takes place by itself and does not require much help, but various risk factors such as infection have serious impact. B. subtilis, S. aureus, E. coli, $K$. pneumoniae, and $P$. aeruginosa are the most wound infecting pathogens, as the open wound provides the favorable conditions for microbial growth [22]. Our study indicated the antimicrobial potency of $I$. coccinea methanol extract (IxME) against most common wound infecting pathogens, for example, B. subtilis $(\mathrm{MIC}=0.125 \mathrm{mg} / \mathrm{mL}), K$. pneumoniae $(\mathrm{MIC}=$ $0.25 \mathrm{mg} / \mathrm{mL})$, and $P$. aeruginosa $(\mathrm{MIC}=0.50 \mathrm{mg} / \mathrm{mL})$ as compared to other solvent extracts (Table 1), corroborating with the previous reports of antimicrobial potential $[8,11,13]$.

Invading microbes prolonged the inflammatory phase of wound healing by producing toxins and wound exudates and subsequently delayed the granulation tissue formation [22]. Activated polymorphonuclear cells including neutrophiles, leukocytes and mononuclear cell (MNC) like lymphocytes, monocytes, and macrophages phagocytize, and kill all the infecting pathogen. Reactive oxygen species (ROS) are the key product for bactericidal activity of these activated cells. 

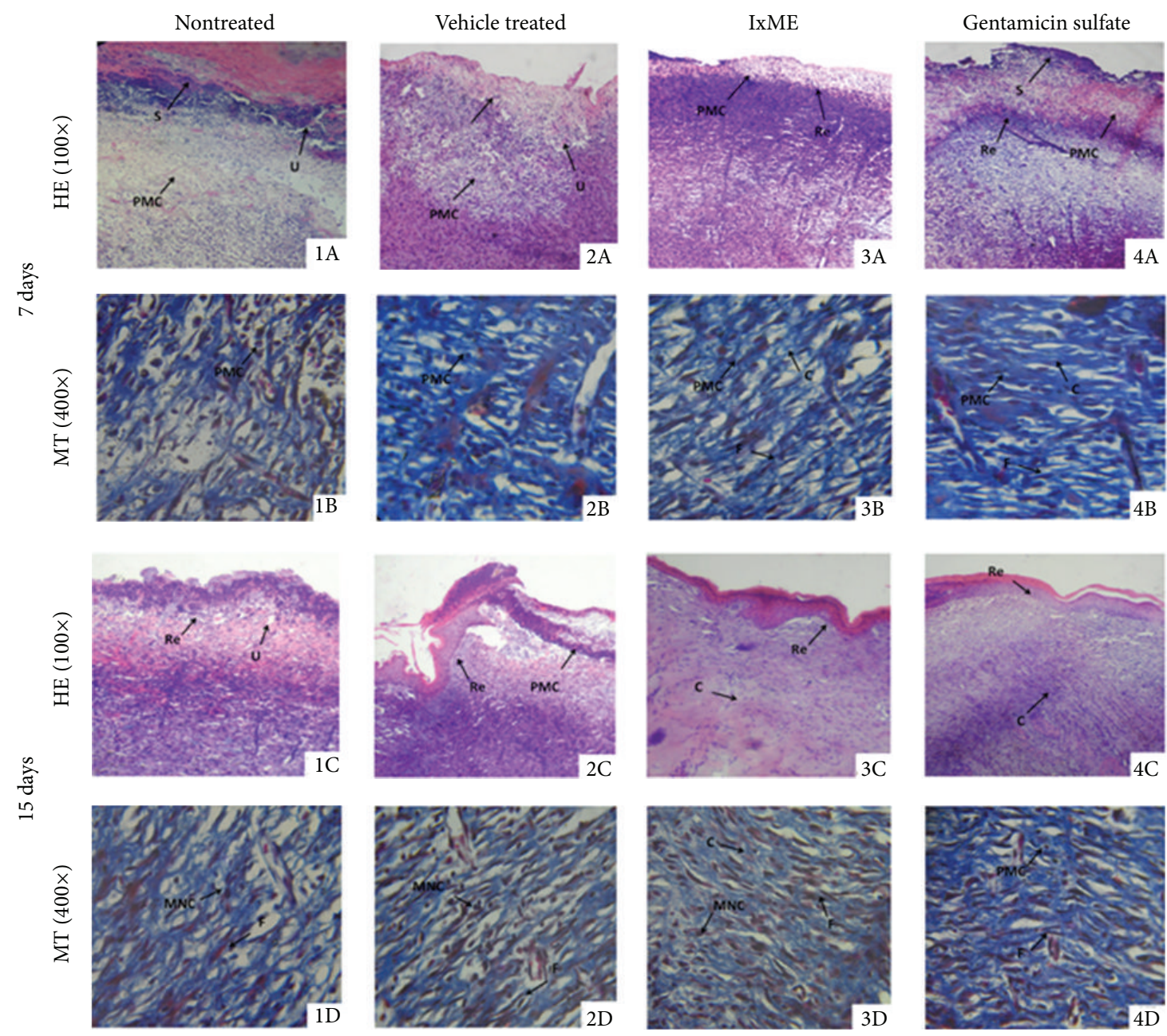

FIGURE 4: Microscopic view of healing wound granulation tissue and remodeling epidermis/dermis in (1) nontreated, (2) vehicle control, (3) IxME, and (4) gentamicin sulfate treated animal groups. Section shows the hematoxylin and eosin stained epidermis and dermis in (A) and (C) (100x) and Masson's trichrome stained dermis in (B) and (D) (400x) of 7- and 15-day postoperative treated animal groups, respectively. The arrows point to the events of wound healing_S: scab; U: ulcer; Re: reepithelization; F: fibroblast; PMC: polymorphonuclear cells; MNC: mononuclear cells; C: collagen; and NV: neovascularization.

ROS like $\mathrm{HO}^{-2}, \mathrm{HO}^{-}$, and $\mathrm{O}^{2-}$, although in low concentrations sterile the wound fibrin clot matrix and are the important determinant of wound angiogenesis [23]. Whereas, the profuse ROS not only damage extracellular structure proteins, lipids, and DNA but also stimulate signal transduction pathways to prolong the inflammatory phase of wound healing. Many scientific publications have proven the beneficial effect of different plant-based antioxidants on wound repair process $[24,25]$ and our findings of free radical scavenging activity (DPPH, SRSA, FRAP, and FCR) in methanol and water I. coccinea extracts revealed that this plant may be useful in wound healing (Figure 1 and Table 2).

The proliferation phase of wound healing involves formation of granulation tissue, synthesis and deposition of collagen fibers, and reepithelialization. In the late phase of inflammation, the activated macrophages initiate the proliferation phase, that actively progressed by the infiltrating fibroblasts. Fibroblast cells synthesize the collagen fibers and other cytoskeleton matrix components [26, 27]. In vitro fibroblast proliferation assay for I. coccinea revealed the toxic effect of IxPE and IxCE as the cell viability decreased $(<80 \%$ to $0.5 \%$ FBS) with increasing concentrations (Figure 2(a)). IxPE decreased cell population could be due to the presence of proliferation inhibitory components in I. coccinea petroleum ether extract, which also synergized the $\mathrm{H}_{2} \mathrm{O}_{2}$-induced fibroblast cell death. Whereas, IxCE at $100 \mu \mathrm{g} / \mathrm{mL}$ decreased the cell population below $80 \%$ was considered as cytotoxic. In the biphasic proliferation response of IxCE, IxME, and IxWE, the inhibitory effect at higher concentrations might be due to accumulation of growth inhibitory components of respective crude extract (Figure 2(a)). IxME and IxWE showed the concentration dependent protection and effectively antagonized the $\mathrm{H}_{2} \mathrm{O}_{2}$-induced cell death (Figure 2(b)) and this protective effect might be due to antioxidant properties of the extracts (Table 2). The above findings of in vitro fibroblast proliferation and protection against $\mathrm{H}_{2} \mathrm{O}_{2}$ coincide with the previous reports of different medicinal plants $[1,3-5]$. However, the IxCE did not show any in vitro antioxidant activity (DPPH, 


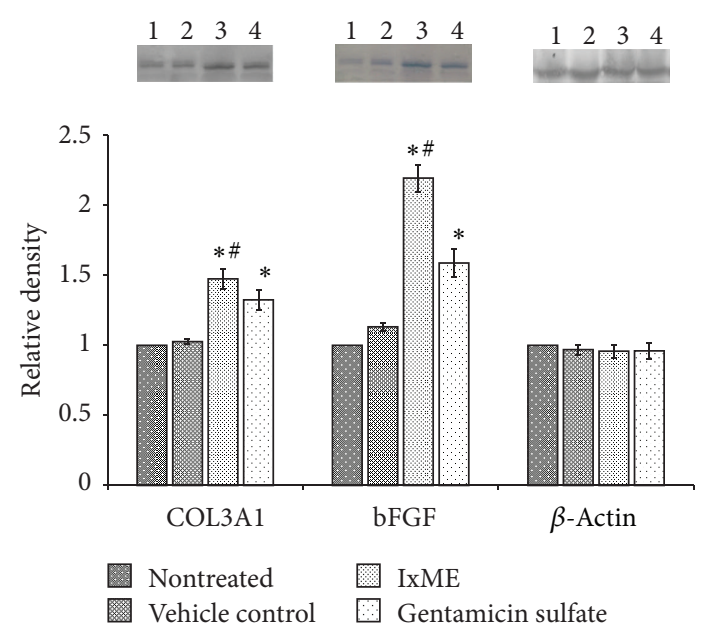

(a)

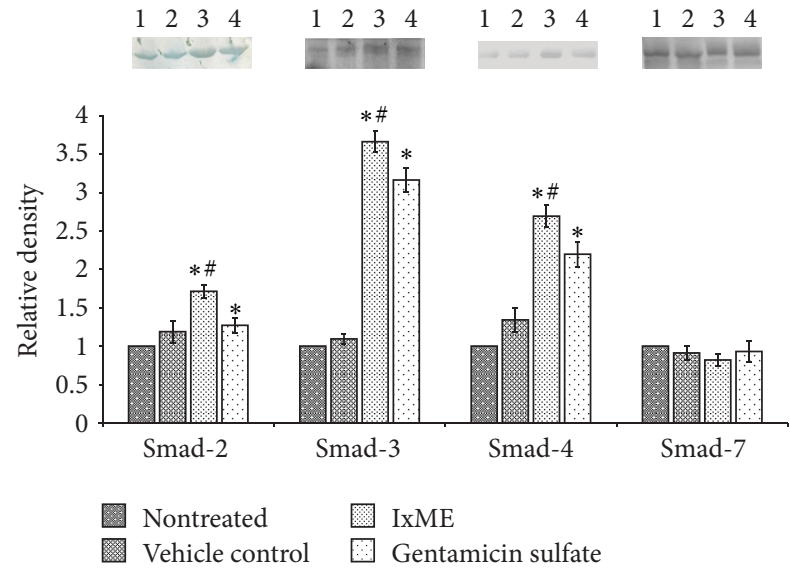

(b)

FIGURE 5: Effect of I. coccinea methanol extract (IxME) on COL3A1 and bFGF Smad-2, -3, -4, and -7 protein expressions on day 7 (seven) in wound tissues, detected by western blot. Lane (1) nontreated, (2) vehicle control, (3) IxME, and (4) gentamicin sulfate treated animal group, respectively. Values are expressed as mean \pm SD. Asterisk $(*)$ indicates significantly different $(P<0.05)$ as compared to the nontreated and vehicle treated groups. Hash $(\#)$ indicates significantly different $(P<0.05)$ as compared to gentamicin sulfate treated group.

SRSA, andFRAP); thereby the protective effect against $\mathrm{H}_{2} \mathrm{O}_{2}$ induced oxidative stress could be due to the intracellular antioxidant enzymes (superoxide dismutase, glutathione peroxidase, catalase, etc.) inducing activity.

From the above in vitro antimicrobial, antioxidant, and fibroblast cell proliferation studies it was observed that $I$. coccinea methanol extract possesses the highest activity as compared to other extracts. Keeping in view of the above findings, IxME $(2.5 \% \mathrm{w} / \mathrm{w})$ was further evaluated for in vivo wound healing activity in Wistar rat in circular excision model.

In wound repair process, the centripetal movements of surrounding epithelial tissues (rallied by the maturing extracellular matrix) close the wound opening [27]. Collagen is a major component of extracellular matrix and wound repair process depends on the regulated production and deposition/maturation of new collagen. Hydroxyproline is a basic constituent of collagen structure and its content is an index of collagen synthesis. The periodic assessment of wound area showed that the topical application of IxME significantly accelerated the wound contraction rate and hydroxyproline content as compared to nontreated and hydrogel vehicle treated groups. The wound contraction rate for IxME was even faster than gentamicin treated group, although the data was not significant (Figure 3). Fibroblasts in granulation tissue regulate the production, deposition, and their subsequent maturation of collagen fibers that impart physical strength to the tissue. Histopathological examination of IxME treated tissue on 7 and 15 postoperative days showed the well organized wound healing with prominent macrophage and fibroblast infiltration. Reepithelialization was also higher with perfuse collagen deposition in mature dermis as compared to nontreated and vehicle control, both (Figure 4).

During proliferation phase, various secreted chemotactic molecules and growth factors such as transforming growth factor- $\beta$ (TGF- $\beta$ ), basic fibroblast growth factor (bFGF), and platelet derive growth factor (PDGF) control the motion of macrophage/fibroblasts [27, 28]. bFGF promotes the neovascularization in granulation tissue to increase oxygen supply that facilitates the collagen production and maturation. Released TGF- $\beta$ bounds to the extracellular fibroblast TGF$\beta$ receptors and initiates the TGF- $\beta$-Smad mediated collagen production. A complex interplay of Smad family proteins (Smad-2, -3, -4, and -7; TGF- $\beta$ type I receptor kinases substrate) transduced the receptor signals to specific target gene and regulate the synthesis of collagen in granulation tissue $[28,29]$. The mechanism of collagen production through Smad mediated signaling pathway in the granulation fibroblast has been revealed earlier [22, 28, 29] and the present findings of western blot analysis showed that IxME hydrogel topical application significantly upregulated the expression of bFGF, COL3Al, and Smad-2 and - 4 proteins as compared to gentamicin sulfate and control groups, whereas the expression of Smad-7, the inhibitory protein was unaltered (Figure 5). Histopathological examination and expression of tissue protein (bFGF and COL3A1) supported the in vitro findings of fibroblast proliferation potential of IxME.

\section{Conclusion}

The present study revealed that $I$. coccinea methanol extract mediated wound healing activity may be a combine effect of antimicrobial, antioxidant and fibroblast proliferating properties, which is also supported by the in vitro and in vivo experimental studies.

\section{Conflict of Interests}

The authors declare that they have no conflict of interests. 


\section{Acknowledgments}

Financial support to A. Upadhyay in the form of Research Fellowship by DRDO, Ministry of Defence, Government of India, is gratefully acknowledged. Authors are also thankful to Defence Research Laboratory, Tezpur, Assam, India, and Birla Institute of Technology, Mesra, Ranchi, India, for providing necessary support for carrying out the research work.

\section{References}

[1] P. J. Houghton, P. J. Hylands, A. Y. Mensah, A. Hensel, and A. M. Deters, "In vitro tests and ethnopharmacological investigations: wound healing as an example," Journal of Ethnopharmacology, vol. 100, no. 1-2, pp. 100-107, 2005.

[2] B. Kumar, M. Vijayakumar, R. Govindarajan, and P. Pushpangadan, "Ethnopharmacological approaches to wound healingexploring medicinal plants of India," Journal of Ethnopharmacology, vol. 114, no. 2, pp. 103-113, 2007.

[3] R. Thakur, N. Jain, R. Pathak, and S. S. Sandhu, "Practices in wound healing studies of plants," Evidence-Based Complementary and Alternative Medicine, vol. 2011, Article ID 438056, 17 pages, 2011.

[4] A. Adetutu, W. A. Morgan, and O. Corcoran, "Antibacterial, antioxidant and fibroblast growth stimulation activity of crude extracts of Bridelia ferruginea leaf, a wound-healing plant of Nigeria," Journal of Ethnopharmacology, vol. 133, no. 1, pp. 116119, 2011.

[5] K. Annan and P. J. Houghton, "Antibacterial, antioxidant and fibroblast growth stimulation of aqueous extracts of Ficus asperifolia Miq. and Gossypium arboreum L., wound-healing plants of Ghana," Journal of Ethnopharmacology, vol. 119, no. 1, pp. 141144, 2008.

[6] B. S. Nayak, A. L. Udupa, and S. L. Udupa, "Effect of Ixora coccinea flowers on dead space wound healing in rats," Fitoterapia, vol. 70, no. 3, pp. 233-236, 1999.

[7] W. D. Ratnasooriya, S. A. Deraniyagala, G. Galhena, S. S. P. Liyanage, S. D. N. K. Bathige, and J. R. A. C. Jayakody, "Antiinflammatory activity of the aqueous leaf extract of Ixora coccinea," Pharmaceutical Biology, vol. 43, no. 2, pp. 147-152, 2005.

[8] N. Selvaraj, B. Lakshmanan, P. M. Mazumder, M. Karuppasamy, S. S. Jena, and A. K. Pattnaik, "Evaluation of wound healing and antimicrobial potentials of Ixora coccinea root extract," Asian Pacific Journal of Tropical Medicine, vol. 4, no. 12, pp. 959-963, 2011.

[9] P. G. Latha and K. R. Panikkar, "Cytotoxic and antitumour principles from Ixora caccinea flowers," Cancer Letters, vol. 130, no. 1-2, pp. 197-202, 1998.

[10] J. Annapurna, P. V. S. Amarnath, D. A. Kumar, S. V. Ramakrishna, and K. V. Raghavan, "Antimicrobial activity of Ixora caccinea leaves," Fitoterapia, vol. 74, no. 3, pp. 291-293, 2003.

[11] T. O. Idowu, A. O. Ogundaini, A. O. Salau, E. M. Obuotor, M. Bezabih, and B. M. Abegaz, "Doubly linked, A-type proanthocyanidin trimer and other constituents of Ixora caccinea leaves and their antioxidant and antibacterial properties," Phytochemistry, vol. 71, no. 17-18, pp. 2092-2098, 2010.

[12] A. Torey, S. Sasidharan, L. Y. Latha, S. Sudhakaran, and S. Ramanathan, "Antioxidant activity and total phenolic content of methanol extracts of Ixora caccinea," Pharmaceutical Biology, vol. 48, no. 10, pp. 1119-1123, 2010.

[13] L. Y. Latha, I. Darah, K. Jain, and S. Sasidharan, "Pharmacological screening of methanolic extract of Ixora species," Asian
Pacific Journal of Tropical Biomedicine, vol. 2, no. 2, pp. 149-151, 2012.

[14] K. R. Khandelwal, Practical Pharmacognosy, Techniques \& Experiments, Nirali Prakashan, 11th edition, 2004.

[15] E. A. Hayouni, K. Miled, S. Boubaker et al., "Hydroalcoholic extract based-ointment from Punica granatum L. peels with enhanced in vivo healing potential on dermal wounds," Phytomedicine, vol. 18, no. 11, pp. 976-984, 2011.

[16] I. M. C. Brighente, M. Dias, L. G. Verdi, and M. G. Pizzolatti, "Antioxidant activity and total phenolic content of some Brazilian species," Pharmaceutical Biology, vol. 45, no. 2, pp. 156-161, 2007.

[17] I. Süntar, E. K. Akkol, F. S. Enol, H. Keles, and I. E. Orhan, "Investigating wound healing, tyrosinase inhibitory and antioxidant activities of the ethanol extracts of Salvia cryptantha and Salvia cyanescens using in vivo and in vitro experimental models," Journal of Ethnopharmacology, vol. 135, no. 1, pp. 7177, 2011

[18] X. H. Wang and J. T. Dai, "A comparative study on antioxidant activity of water and ethanol extracts of ten Chinese herbs," Journal of Medicinal Plants Research, vol. 6, no. 11, pp. 2210-2215, 2012.

[19] S. Maurya and D. Singh, "Quantitative analysis of total phenolic content in Adhatoda vasica nees extracts," International Journal of PharmTech Research, vol. 2, no. 4, pp. 2403-2406, 2010.

[20] OECD guideline for testing of chemicals-402, Acute Dermal Toxicity, 1987.

[21] A. Upadhyay, P. Chattopadhyay, D. Goyary, P. M. Mazumder, and V. Veer, "Eleutherine indica L. accelerates in vivo cutaneous wound healing by stimulating Smad-mediated collagen production," Journal of Ethnopharmacology, vol. 146, no. 2, pp. 490 494, 2013.

[22] P. G. Bowler, B. I. Duerden, and D. G. Armstrong, "Wound microbiology and associated approaches to wound management," Clinical Microbiology Reviews, vol. 14, no. 2, pp. 244-269, 2001.

[23] M. Schäfer and S. Werner, "Oxidative stress in normal and impaired wound repair," Pharmacological Research, vol. 58, no. 2, pp. 165-171, 2008.

[24] A. Shukla, A. M. Rasik, and G. K. Patnaik, "Depletion of reduced glutathione, ascorbic acid, vitamin $\mathrm{E}$ and antioxidant defence enzymes in a healing cutaneous wound," Free Radical Research, vol. 26, no. 2, pp. 93-101, 1997.

[25] B. P. Mudge, C. Harris, R. R. Gilmont, B. S. Adamson, and R. S. Rees, "Role of glutathione redox dysfunction in diabetic wounds," Wound Repair and Regeneration, vol. 10, no. 1, pp. 52 $58,2002$.

[26] Y. Mimura, H. Ihn, M. Jinnin, Y. Asano, K. Yamane, and K. Tamaki, "Epidermal growth factor induces fibronectin expression in human dermal fibroblasts via protein kinase $\mathrm{C} \delta$ signaling pathway," The Journal of Investigative Dermatology, vol. 122, no. 6, pp. 1390-1398, 2004.

[27] T. Kondo and Y. Ishida, "Molecular pathology of wound healing," Forensic Science International, vol. 203, no. 1-3, pp. 93-98, 2010.

[28] M. Schiller, D. Javelaud, and A. Mauviel, "TGF- $\beta$-induced SMAD signaling and gene regulation: consequences for extracellular matrix remodeling and wound healing," Journal of Dermatological Science, vol. 35, no. 2, pp. 83-92, 2004.

[29] J. Massagué and R. R. Gomis, "The logic of TGF- $\beta$ signaling," FEBS Letters, vol. 580, no. 12, pp. 2811-2820, 2006. 

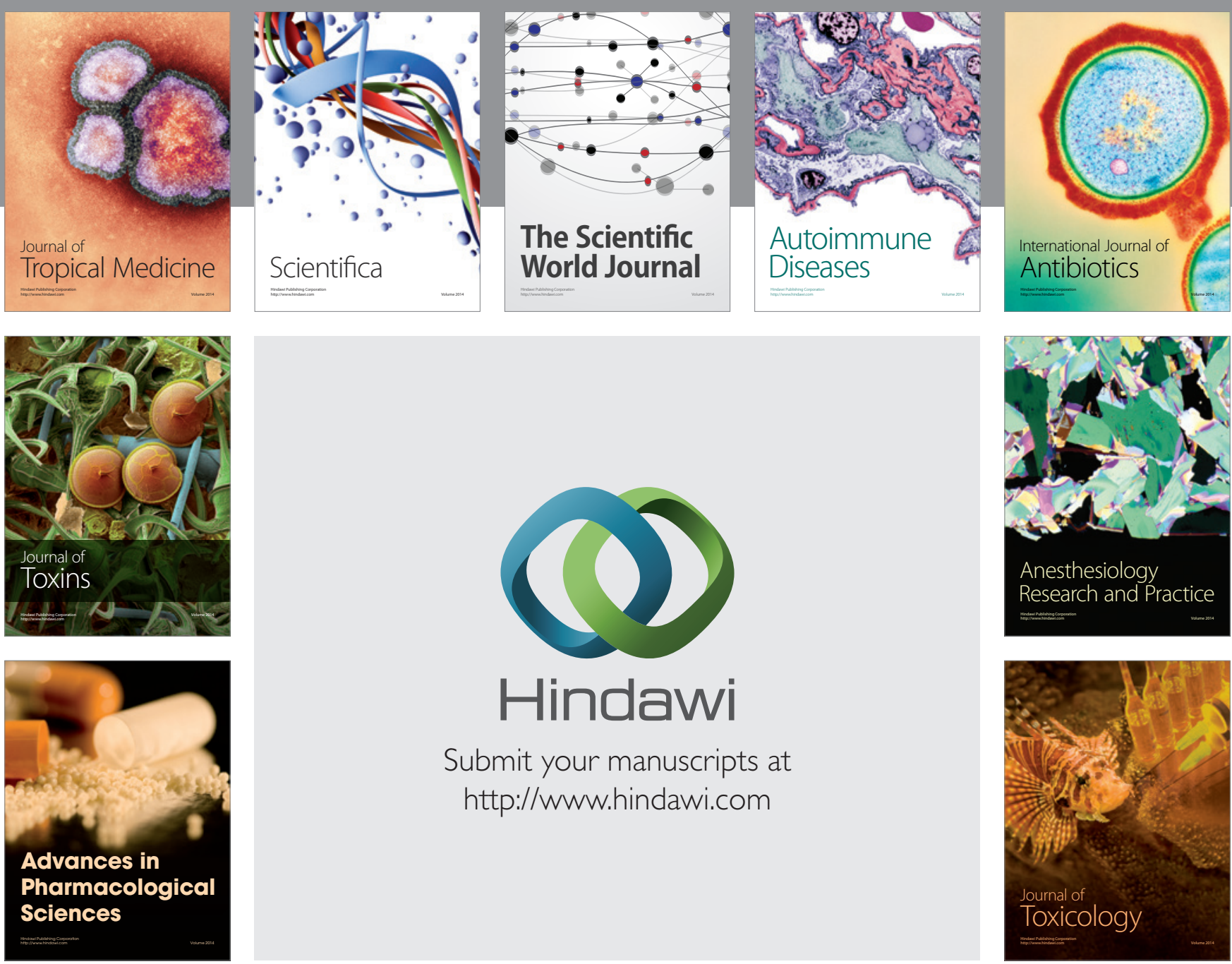

\section{Hindawi}

Submit your manuscripts at

http://www.hindawi.com
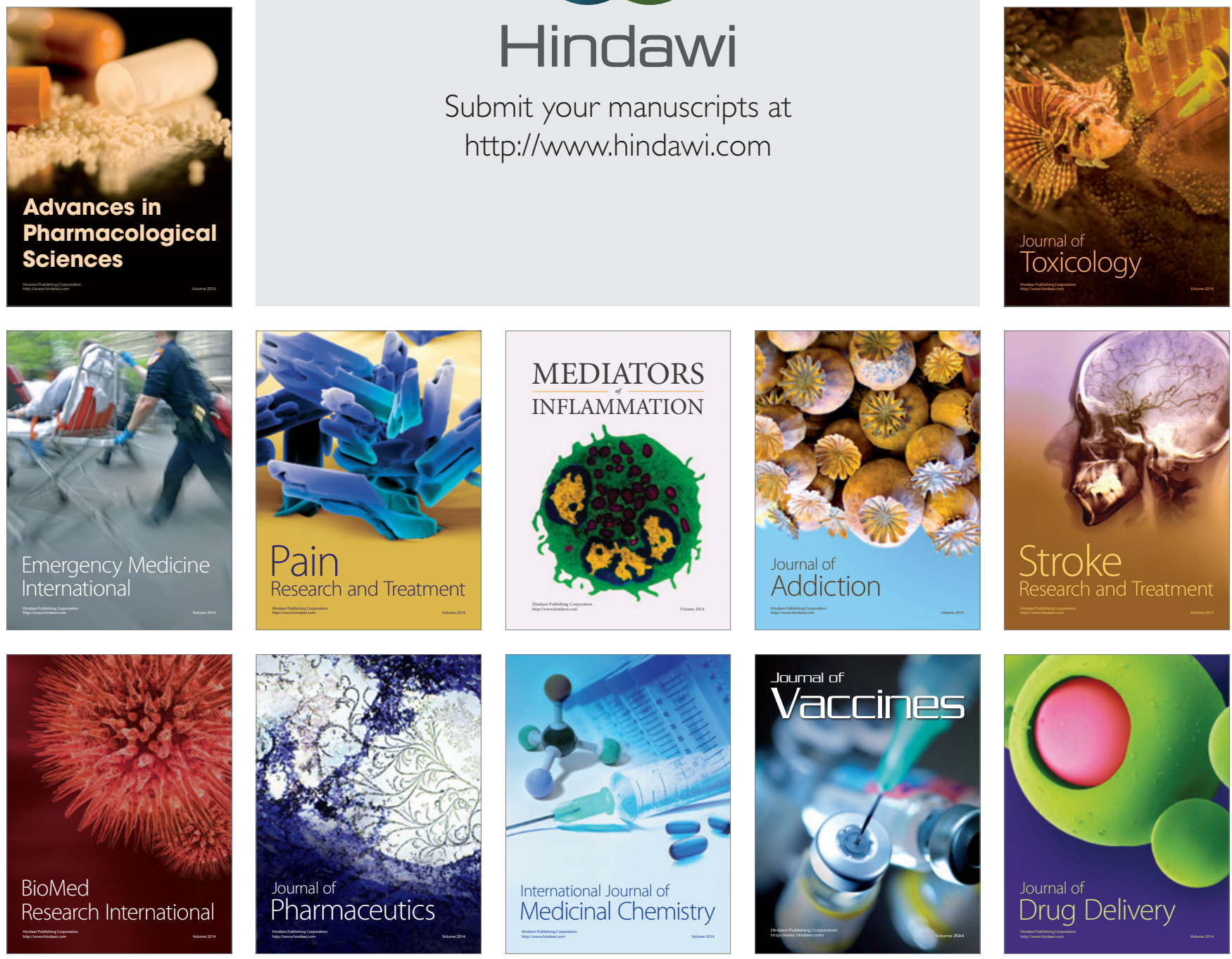